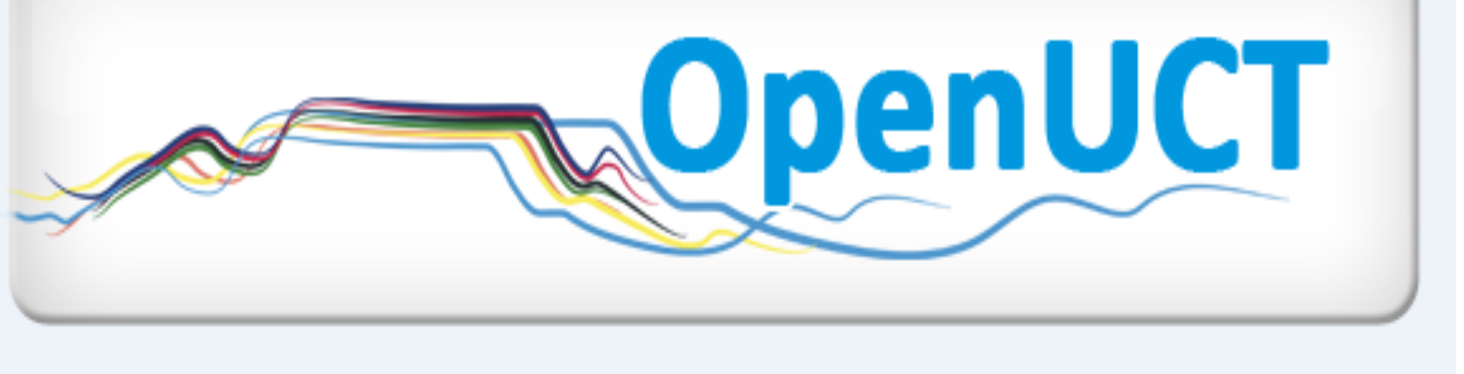

This is the post-print of Craig, T. S. 2013. Conceptions of mathematics and student identity: implications for engineering education. International Journal of Mathematical Education in Science and Technology. 44(7): 1020-1029. DOI: 10.1080/0020739X.2013.823521.

It is made available according to the terms of agreement between the author and the journal, and in accordance with UCT's open access policy available:

http://www.openuct.uct.ac.za/sites/default/files/UCTOpenAccessPolicy.pdf, for the purposes of research, teaching and private study. 


\title{
Conceptions of mathematics and student identity: implications for engineering education
}

\author{
Tracy S. Craig \\ Academic Support Programme for Engineers in Cape Town (ASPECT), Centre for Research in \\ Engineering Education (CREE), University of Cape Town, Rondebosch, South Africa
}

\begin{abstract}
Lecturers of first-year mathematics often have reason to believe that students enter university studies with naive conceptions of mathematics and that more mature conceptions need to be developed in the classroom. Students' conceptions of the nature and role of mathematics in current and future studies as well as future career are pedagogically important as they can impact on student learning and have the potential to influence how and what we teach. As part of ongoing longitudinal research into the experience of a cohort of students registered at the author's institution, students' conceptions of mathematics were determined using a coding scheme developed elsewhere. In this article, I discuss how the cohort of students choosing to study engineering exhibits a view of mathematics as conceptual skill and as problem-solving, coherent with an accurate understanding of the role of mathematics in engineering. Parallel investigation shows, however, that the students do not embody designated identities as engineers.
\end{abstract}

Keywords: identity; conceptions of mathematics; engineering education

\section{Introduction}

This article adds to the body of literature available on conceptions of mathematics with its observations that first-year students of tertiary engineering studies can exhibit engineeringappropriate conceptions of mathematics in advance of their development of engineering identity. The cohort of students who took part in the study was engaged in their first year of tertiary engineering studies (civil, electrical, chemical and mechanical). An analysis of interview data using Sfard and Prusak's [1] narrative theory of identity suggested that the students had, in general, not yet developed an 'engineering identity' as is theorized as desirable for completing engineering studies $[2,3]$ yet exhibited a mature conception of mathematics as problem-solving.

Engineering is often understood as being associated with problem-solving. An engineering university degree programme requires students to study and practise a wide range of mathematics such as (depending on the field of study) differential equations and modelling, complex analysis, vector geometry and vector calculus. Since the role of mathematics in the discipline of engineering is as a suite of problem-solving approaches and a problemsolving way of thinking, it befits the student of engineering to possess a conception of mathematics as problem-solving rather than (also possible) as simply a list of algorithms 
or the oft-cited 'toolbox' of discrete objects. Other studies [4] have observed that first-year university students of engineering do not understand the role that mathematics will play in their future studies and careers. The role of mathematics in engineering studies differs from its role in future careers, with mathematics frequently playing a large role in studies (for example, courses in vibrations, dynamics, signals and so forth) and playing far less of a role in post-university careers. In the interviews specific to the study discussed in this article, the two future uses were conflated in one question, in part because the interview protocol had to be one-size-fits-all for students across faculties.

It has been argued that students who identify with their programme of study will experience greater affiliation with the subjects they study, be more motivated to study, be engaged in active meaning-making and have greater chances of success than students who do not identify with their chosen programme of study.[5,6] Extrapolating within this paradigm, if students consider themselves to be engineers or in some sense identify with the profession of engineering, they stand a greater chance of ultimately graduating than if they cannot claim such identity. An alternate construction, using the model of Gee's discourse,[7] claims that students who share understandings and values with their lecturers have a greater chance of succeeding; they are recognized as being in the discourse and enact the appropriate identity as legitimate student engineers.[8]

The literature focusing on entry-level cohorts of undergraduate engineering students tends to focus on skills and knowledge in mathematics and, in general, to find the levels of such skills and knowledge both diverse across a cohort and weaker than teaching staff would prefer.[9-11] Certainly there is cause for concern about (or at least awareness of) entry-level skills and their implications; however, one must avoid the danger of conflating the notions of mathematical skill and mathematical conception, as described in this article. A student can have weak algebraic skills yet still hold a problem-solving conception or construction of mathematics, as illustrated by several of the students in this study. The literature on more over-arching conceptions of mathematics is scarce and the literature on engineering identity is scarcer still. The studies related to engineering identity have shown that affiliation with an engineering discipline increases with the development of a 'positional' identity as an engineering student.[12,13] Specific to South Africa, 'social identity' is found amongst many black engineering students, with students choosing to study engineering for its potential to have positive impact on their home communities.[14] There is definitely scope for further research into the incoming and developing identities of engineering students. In this article, we are working from the well-reasoned premise espoused by Cobb and colleagues $[5,6]$ that identity aids success, but a robust body of data supporting that argument has not been found by this author.

The study discussed in this article reveals that this particular cohort, while exhibiting the conception of mathematics that is arguably concomitant with engineering identity, does not in general display signs of an engineering identity despite great motivation to succeed. The article concludes by considering the consequences of these observations on pedagogy.

\section{The students}

\subsection{Background - home and community}

The majority of the 15 students in the study (introduced in greater detail below) grew up in homes and community circumstances not conducive to learning.[15-17] Many grew up in single-parent homes, some were raised by grandparents. Certain students' parents or primary caregivers did not have qualifications beyond primary school. For instance, 
neither of John's1 parents, had any formal schooling at all. Most of the students grew up in 'townships', poorly resourced and serviced urban areas usually recognizable by shacks and lack of permanent housing. Drug use and violence were prevalent in the communities of most of the students.

In the questionnaire that the students completed at the beginning of their first year at university, a cluster of questions was designed to probe the home, school and community circumstances of the students. Examples of responses with respect to the local community include reporting

- public selling and/or use of drugs occurred 'very often' (Senzo, Michela, Philile and Chris);

- public physical violence, including shootings and stabbings, occurred 'often' or 'very often' (Chris, John and Senzo);

- muggings occurred 'often' or 'very often' (Chris, Rethabile, Siphilisiwe, Ndiphiwe, Michela, Philile and Senzo);

- people in the community were 'often' or 'very often' hungry and/or unemployed (Rethabile, Michela, Philile, Chris, Senzo, John, Ndiphiwe and Siphilisiwe).

Among the students in the study, all of them were not subjected to the same level of poverty and danger; certain students stand out as having grown up in areas which were particularly violent and dangerous. The schools these students attended often did little to offset the threat to learning imposed by the community outside the school.

\subsection{Background - schooling}

The schools attended by the students display a range of resources. While some schools were relatively well resourced with dedicated teachers, a number of the students suffered from a lack of teachers in their final years at high school and poorly resourced schools in general. Chris, for instance, lacked teachers for four subjects in his final school year. Senzo had three successive mathematics teachers in his final year, the first having to teach older material to make up for a lack of teachers in previous years. Philile and Senzo's schools did not have sufficient textbooks for all learners. Chris, in his final year at school, had no access to newspapers, magazines or leisure books. There is almost no end to the list of environmental characteristics hostile to an atmosphere of learning.

Consider that these students culminated their schooling with applying to, and being accepted into, a prestigious university. A common thread in almost all of the interviews was the hard work the students had to put into studying to achieve good school-leaving results; how they got up at 4 am to study, how they formed study groups where they taught one another the work their schools were failing to teach them and how they attended weekend workshops organized by other schools or educational institutions. The students taking part in the research project, of which this article forms a part, are all enrolled in one of the university's academic development programmes, due in part to their school-leaving results not being quite high enough to allow them access to mainstream studies. That their school-leaving results, specifically mathematics and general science, were as high as they were is a testament to their academic proficiency, hard work and tenacity and that has been recognized by their acceptance into the university. 


\subsection{The academic development programme research project (ADPRP)}

\subsubsection{The population}

The cohort of students involved in the study were all enrolled in 2009 in the Academic Support Programme for Engineering in Cape Town (ASPECT). ASPECT is the academic development group in the Faculty of Engineering and the Built Environment at the University of Cape Town (UCT). The majority of students had a so-called previously disadvantaged educational background, had narrowly missed making the 'points' requirement for enrolling for a mainstream engineering degree and were admitted to ASPECT on an individual basis on the strength of their school-leaving results. The cohort discussed in this article consisted of seven women and eight men. Two spoke English as a main language. None of the students were white.

\subsubsection{The larger study}

The research question discussed in this article formed part of a longitudinal study at the UCT, which began in 2009 and continues at the time of writing.[15] The larger study focuses on access and throughput of students from disadvantaged educational backgrounds, timed to coincide with the entrance to UCT of the first cohort of learners in South Africa who had been educated in a curriculum based on the principles of outcome-based education. They are part of a very small number of Grade 12 school leavers (on average $11 \%$ of black students) who qualify for entry to university. The key question of the larger study is 'What facilitates or hinders the 2008 National Senior Certificate students' access to and/or success in higher education study?' It is hoped that this article will inform the larger project.

\subsubsection{The data sources}

Each student taking part in the study completed (1) a background biographical questionnaire that aimed to establish home, school and community social conditions and study and social habits (informing Sections 2.1 and 2.2 in this article), (2) an open-ended questionnaire that required them to write about their histories of studying language and mathematics (hereafter simply 'histories') and (3) took part in an interview that investigated how students were negotiating the school-university transition. Within the interview the students were asked 'What role do you think mathematics is likely to play in your future studies and future career?' as well as other questions related to mathematics. Their answers to these questions as well as their histories are the data analysed in this report; they were lent depth by the students' discussions of their family and educational backgrounds.

\section{Methodology and results}

The data were interrogated using two complementary analyses. First, a selected fragment of the interview data was coded using a 'conceptions of mathematics' scheme from the literature.[18,19] The coding scheme is presented here and the results of the coding in this research project are presented and briefly discussed. The second analysis draws on the interview and history data to attempt to understand the students' designated identities as defined through the lens of Sfard and Prusak's [1] narrative theory of identity. The narrative notion of identity is particularly fitting for interview data and contrasts with other identity theories in that it does not postulate a core identity of which the interview narrative is an indicator, but posits instead that the narrative is the identity. A description of Sfard and 


\section{T.S. Craig}

Table 1. Categorization scheme developed by Wood et al.[13].

Category

No idea

Procedural skills

Concentual skills

Professional skills
Description

Students do not know what role mathematics will play; students refer to mathematics simply as a structural part of their degree

Mathematics is a tool box of procedures to be selected from as needed; view of the role of mathematics not the depth or complexity of mathematics itself; only certain isolated skills or techniques are seen as relevant

Studying mathematics develops conceptual skills such as logical thinking or problem-solving; problem-solving skills are useful for deepening understanding in other disciplines or areas

Mathematics is seen as playing a substantial role but no specific role is stated; possibly students consider mathematics to be such an integral part of their studies that it cannot be separated from them

Prusak's identity theory is offered here and the results of the analysis are presented and briefly discussed.

\subsection{Conceptions of mathematics}

Student responses to the question 'What role do you think mathematics is likely to play in your future studies and future career?' were coded using the tool shown in Table 1.

The categories in Table 1 emerge from a prior study conducted by a research team (not including myself) across five universities on five continents, in which almost 1200 students studying mathematics were asked the questions:

-What is mathematics?

-What part do you think mathematics will play in your future studies?

-What part do you think mathematics will play in your future career?

Results have been reported and discussed in $[18,19]$. Further discussion of interest can be found in [20-22] although not using the categorization scheme presented in Table 1. Student responses were open-ended and were coded in categories developed through phenomenographic analysis. The similarity of the questions above (studies and career separate) and the questions in the interviews of this article (studies and career considered together) allowed the use of the categorization scheme in our study.

\subsubsection{Results - conceptions of mathematics}

In the ADPRP interview, the students were asked 'What role do you think mathematics is likely to play in your future studies and future career?'. Using the coding scheme provided in Table 1, student responses to the question were coded and the results are displayed in Table 2. Three students gave responses which could be coded into two categories, discussed below.

The observation of particular focus in this article is that the majority of students ( 9 of $15)$ answered the question with 'conceptual skill' responses, such as 
Table 2. Coded student responses to the conceptions question.

$$
\text { Professional skills } \quad \text { Conceptual skills } \quad \text { Procedural skills } \quad \text { No idea }
$$

Chris

Nwabisa

$X$

Senzo

Fatima

Leonard

Rethabile

John

Tsegoa

Simphiwe

Siphilisiwe

Ndiphiwe

Michela

Lesegoa

Philile

Kwezia

Total

$\begin{array}{cc} & X \\ X & X \\ & \\ (X) & X \\ & X \\ X & X \\ X & X \\ (X) & X \\ & X \\ 4(+2) & X\end{array}$

X

$x$

$X$

$x$

$x$

X

$X$

$X$

9

$0(+1)$

a Three students' responses were coded in two different categories, discussed below.

Philile: I think Maths teaches you how to think most of the while and logic out situations. I don't really think it's about the calculations.

John: Maths involves a lot of solving problems and maybe if you see a problem, how you can approach that problem without even thinking how, wasting a lot of time maybe spending hours how you can do this problem, I can say Maths is training my mind so that it can be maybe, I can use it everywhere because Maths, you can't say Maths only involves numbers and stuff because I can use even if I, I can use Maths in a lot of places.

The students' stated claim that they understand mathematics to represent a way of thinking and developing problem-solving skills is in line with what is understood to be a well-developed engineering conception of mathematics.[23-25] Assuming that first-year students have an immature understanding of what mathematics is, simply because they are in their first year of tertiary study, is revealed to be a naive or incomplete view. This is a view rarely found in the education literature, but is prevalent amongst teaching staff.

A number of students view mathematics as a 'professional skill'.

Rethabile: A huge role, ja, I'm supposed to be doing Maths from this year up till next year and then there is an elective of doing Maths third year, so I'm thinking I'm going to do Maths third year as well . . . you know even if I don't do Maths I feel like the concepts of Maths are going to creep up in some areas so then I would rather just do and get the full detailed explanations of things. . . . a major role because now soon l'll be an Engineer if all goes well and they measure things and it's going to play a very important role, it's going to be my life, I think.

Three students gave responses which were coded in two categories, one of them was Lesego.

Lesego: It's going to play a big role because a lot of Civil Engineers they like, they go deep into Maths ... like Maths is also, like it's also not just about applying Maths, it's also when you do Maths, it's a way of thinking as well, so ja, that it will help also indirectly (Coded as 'professional' and 'conceptual' with 'conceptual' considered the more fitting category). 


\section{T.S. Craig}

\subsection{Identity}

To explore the possibility that the students possessed strong identities as engineers, the interview and history data were interrogated. Sfard and Prusak's [1] construction of identity as narrative was employed to this end. They define identity 'as collections of stories about persons or, more specifically, as those narratives about individuals that are reifying, endorsable and significant'.[1, p.16] Sfard and Prusak deliberately avoid mention of some sort of internal identity which the interviewee is talking about through narratives of various kinds. They call this an 'essentialist vision' of identity and consider the notion of identity being something that is extra discursive and independent of action to be both untenable (it gives us no idea of what to look for) and potentially harmful (descriptors can become self-fulfilling). Instead they define identity as narrative, with two primary forms. Actual identity is a collection of stories about the actual state of affairs, expressed in the present tense and formulated as fact. Designated identity is a collection of stories about a state of affairs expected to be the case in the future, having the potential to become part of one's identity; expressed in future tense, or expressed in words evoking obligation, commitment, necessity or wish.

\subsubsection{Results - identity}

The interviews and histories were combed for instances when the students had spoken about themselves in present and future tenses. Examples of excerpts include:

Ndiphiwe: I know that when I graduate from UCT I will be one of the best people in the corporate world and I would have the degree that will allow me, it will open the doors for me in the world.

Simphiwe: I just guess I'm not a people's person, something like that, I prefer my own space other than being out there.

Tsego: Well I can say I'm a socialite, I'm used to like meeting new people and I enjoy it so coming to UCT hasn't really been a shock as such, it's normal to meet new people so I'm used to it.

John I'm proud of being a Xhosa and I'm sure I speak to every Xhosa but a person maybe from overseas can't know Xhosa, English is the only language that that person can understand so English is the language that I have to speak.

The instances of students speaking about themselves in either present or future tense ranged from 41 to 102 items per student, with an average of 63 . Using the notation of Sfard and Prusak,[1] the utterances by the students were about the student himself/herself and were spoken to the interviewer: student Studentinterviewer, while the utterances included here were chosen by me to be read by you, the reader: Researcher (Student StudentInterviewer) Reader . Choosing only the items definable as Student StudentInterviewer and resisting reading between the lines (which was an ever-present danger) the designated identities, which can be assigned to the students are shown in Table 3.

Table 3 is necessarily a highly distilled version of lengthier discussion in the original interviews. It can be argued from the body of interview data which informed Table 3 that the students in this cohort do not have well-developed engineering identities. Instead of choosing to study engineering because they already have a good idea of what engineers do and can see themselves in that role, most are choosing to study engineering for its potential 
Table 3. Designated identity as apparent through interview and history data.

\begin{tabular}{|c|c|}
\hline Student & Designated identity \\
\hline Chris & Studying engineering because it is a useful degree to have \\
\hline Nwabisa & Studying engineering because it is a respected and widely applicable degree \\
\hline Senzo & $\begin{array}{l}\text { Wanted to study accounting, engineering was essentially random second choice, is } \\
\text { happy there but still figuring it all out }\end{array}$ \\
\hline Fatima & $\begin{array}{l}\text { Well defined identity as civil engineer. Knows what is involved (through friend's } \\
\text { father) and wants nothing else }\end{array}$ \\
\hline Rethabile & Identifies as engineer, through programmes seen on television \\
\hline John & $\begin{array}{l}\text { Interesting comments on how engineering is the only known degree back home, that } \\
\text { coming to UCT has shown him many other avenues. Apparently happy with his } \\
\text { choice, but there is little looking into the future, all a focus on the here and now. }\end{array}$ \\
\hline Tsego & $\begin{array}{l}\text { Tsego sees herself as someone working in a lab doing chemistry. As such she applied } \\
\text { to medicine (first choice) and chemical engineering (second choice) }\end{array}$ \\
\hline Simphiwe & $\begin{array}{l}\text { Simphiwe actually wants to be a pilot, but somehow managed to get a bursary to study } \\
\text { metallurgy, which has translated into a chemical engineering degree. She is not very } \\
\text { committed to the degree. }\end{array}$ \\
\hline Siphilisiwe & $\begin{array}{l}\text { Her father has an engineering degree and Siphilisiwe going to university at all does } \\
\text { not seem to have been debatable - perhaps engineering is her father's influence? No } \\
\text { sign of specific engineering identity and she possibly regrets her choice. }\end{array}$ \\
\hline Ndiphiwe & No indication of why engineering. Mentions working in the 'corporate' world. \\
\hline Michela & $\begin{array}{l}\text { Studying engineering because a bursary to do so was imposed upon her without } \\
\text { application through her school. }\end{array}$ \\
\hline Lesego & Studying engineering as good training to be a businessman - owner of restaurants. \\
\hline Philile & Studying engineering because he was convinced to by someone else. \\
\hline Kwezi & $\begin{array}{l}\text { Very keen to come to UCT. Sees himself as efficient member of a(an engineering?) } \\
\text { company. }\end{array}$ \\
\hline Leonard & $\begin{array}{l}\text { He has chosen engineering over several other careers after research during a gap year. } \\
\text { He finds engineering interesting. }\end{array}$ \\
\hline
\end{tabular}

role in socio-economic mobility,[17] a reason that is both justified and commendable. However, analysing the students' responses to the question 'What role do you think mathematics is likely to play in your future studies and future career?', it was determined that the students have a 'conceptual skill' view of mathematics, an analytic conception of mathematics [21] in line with the mathematical understanding we, as engineering educators, want our students to develop during their studies.

It cannot be the case that the students' well-developed engineering identities are endowing them with this analytic conception of mathematics. Neither is it the case that secondary schooling is supportive of anything other than an algorithmic conception of mathematics, nor indeed much of first-year undergraduate mathematics. The students in this study were eligible to enrol for engineering studies in part because of their high achievements in mathematics and science in secondary school. Parents, teachers or friends were prompted by the students' mathematical achievements to recommend engineering as a programme of study. Are the students in the interviews simply repeating rhetoric inherited from their lecturers? Alternately, perhaps it is the case that the students' conceptual understanding of mathematics is part of the cluster of attributes that cause their mentors and advisors to recognize them as potential engineering candidates.

\section{Implications for teaching and learning}

Perhaps the most important point to draw from the analysis is that the students in the study and, one must assume, students studying engineering more widely, hold different 


\section{T.S. Craig}

conceptions of the role of mathematics in their future studies and career, in agreement with other studies.[19,22] Taking as given the hypothesis that robust development of engineering identity encourages affiliation and engagement with studies, $[2,3,5,6]$ we must regard as valuable any attributes or conceptions contributing to an engineering identity with which a first-year student arrives at university. Many of the students in this study enter university with mature conceptions of mathematics already in place,[26] and are further influenced by the multiple elements of their environment. While their mathematics lecturer can no doubt claim some small part in development, the situation is far more complex.[18] The lack of evidence of well-developed engineering identity among the students implies that the well-aligned view of mathematics in their futures does not stem from a deep understanding of what engineering actually is or values.[14] In addition, while the students might hear a lot about problem-solving in class, it is not what they actually get to do in the class. Going by what they see in the classroom, they would think mathematics is a list of algorithms - the first-year engineering (and science) mathematics course simply have such a curriculum. So it seems the students enter engineering studies with this conception of mathematics at least partly formed. Wolmarans and Collier-Reed [8] observe that students entering engineering studies consider themselves to be problem solvers, yet have a wide range of understandings of what that means in practice. An added complication for the engineering mathematics lecturer is that mathematical problem-solving and engineering problem-solving are not the same.

The research question guiding the cross-faculty longitudinal study of which this article forms one small part is 'What facilitates or hinders the 2008 National Senior Certificate students' access to and/or success in higher education study?'. Making connections between the mathematics covered in the classroom and the mathematics of use in further studies and the engineering workplace benefit an approach to learning associated with broader conceptions of mathematics than simply as a toolbox of algorithms.[18] To draw such connections, the lecturers or teachers themselves need to be informed on the mathematics which will be of future use to the students. Classroom activities and assignments designed with the aim of further developing or taking advantage of a conceptual or professional view of the role of mathematics need to be recognized as authentic by the students. This need for the lecturers to be informed requires the lecturers themselves to be continuously learning and certainly makes teaching more challenging than teaching traditional material, disconnected from workplace reality, year in and year out. In an ideal world, the mathematics lecturer of engineering students is aware of his/her students' conceptions of mathematics and structures learning and teaching activities so as to take advantage of the conceptions which are in line with more advanced engineering values in a bid to encourage engagement, affiliation and success.

\section{Acknowledgements}

Funding from the Andrew W. Mellon Foundation is gratefully acknowledged. I wish to thank Bonani Dube, Zulpha Geyer and Judy Sacks for conducting the interviews and for research assistance.

\section{Note}

1. All student names in this article are pseudonyms.

\section{References}

Sfard A, Prusak A. Telling identities: in search of an analytic tool for investigating learning as a culturally shaped activity. Ed Res. 2005;34(4):14-22.

Allie S, Armien MN, Burgoyne N, Case JM, Collier-Reed BI, Craig TS, Deacon A, Fraser DM, Geyer Z, Jacobs C, Jawitz J, Kloot B, Kotta L, Langdon G, le Roux K, Marshall D, Mogashana 
D, Shaw C, Sheridan G, Wolmarans N. Language as acquiring a discursive identity through participation in a community: a theoretical position on improving student learning in tertiary science and engineering programmes. Eur J Eng Educ. 2009;34(4):359-367.

Stevens R, O'Connor K, Garrison L, Jocuns A, Amos DM. Becoming an engineer: toward a three dimensional view of engineering learning. J Eng Ed. 2008;97(3):355-368.

Varsavsky $C$. The design of the mathematics curriculum for engineers: a joint venture of the Mathematics department and the Engineering faculty. Eur J Eng Educ. 1995;20(3):341-345. Cobb P, Hodge LL. An interpretive scheme for analyzing identities that students develop in mathematics classrooms. 2005. Available from: http://www.udel.edu/educ/whitson/897s05/ files/Cobb_ID.pdf, most recently accessed December 2012.

Cobb P, Gresalfi M, Hodge LL. An interpretive scheme for analyzing the identities that students develop in mathematics classroom. J Res Math Ed. 2009;40(1):40-68.

Gee JP. An introduction to discourse analysis: theory and method. 2nd ed. New York: Routledge; 2005.

Wolmarans N, Collier-Reed BI. Problem-solving discourse models: informing an introductory engineering course. Afr J Res Math Sci Tech Ed. 2010;14(2):28-41.

du Preez J, Steyn T, Owen R. Mathematical preparedness for tertiary mathematics - a need for focused intervention in the first year? Persp Ed. 2008;26(1):49-62.

Bamforth SE, Robinson CL, Croft T, Crawford A. Retention and progression of engineering students with diverse mathematical backgrounds. Teach Math Appl. 2007;26(4):156-166.

Shaw CT, Shaw VF. Attitudes of first-year engineering students to mathematics - a case study. Internat J Math Ed Sci Tech. 1997;28(2):289-301.

Bingolbali E, Monaghan J, Roper T. Engineering students' conceptions of the derivative and some implications for their mathematical education. Internat J Math Ed Sci Tech. 2007;38(6):763-777.

Bingolbali E, Monaghan J. Identity, knowledge and departmental practices: mathematics of engineers and mathematicicans. Proc. 28th PME. 2004;2:127-134.

Jawitz J, Case J. Exploring the reasons South African students give for studying engineering. Int J Eng Ed. 1998;14(4):235-240.

Kapp R, Badenhorst E, Bangeni B, Craig TS, Janse van Rensburg V, le Roux K, Prince R, Pym J, van Pletzen, E. 'Out of order': successful students' negotiation of working-class schooling in post-apartheid South Africa. Persp. Ed. Forthcoming 2014.

Kapp R. Students' negotiations of English and literacy in a time of social change. JAC. 2012;32(3-4):591-614.

Craig TS. Student identity and the need to make classroom mathematics relevant to engineering practice. Proceedings of the First Biennial Conference of the South African Society for Engineering; 2011; Stellenbosch, South Africa;8-15.

Wood LN, Petocz P, Reid A. Becoming a mathematician: an international perspective. London: Springer; 2012. Chapter 4, What do mathematics students say about mathematics internationally? p. 53-74.

Wood LN, Mather G, Petocz P, Reid A, Engelbrecht J, Harding A, Houston K, Smith GH, Perrett G. University students' views of the role of mathematics in their future. Int J Sci Math Ed. 2012;10:99-119.

Wood L, Solomonides I. Different disciplines, different transitions. Maths Ed Res J. 2008;20(2):117-134.

Wood LN, Smith G, Mather G, Harding A, Englebrecht J, Houston K, Perrett G, Hillel J, Petocz $P$, Reid A. Student voices: implications for teaching mathematics. Proceedings of the Third International Conference on the Teaching of Mathematics; 2006; Istanbul, Turkey.

Wood LN. Engineering mathematics - what do students think? ANZIAM J. 2008;49: C513-C525.

Meriam JL, Kraige LG. Engineering mechanics: dynamics. 6th ed. Hoboken (NJ): Wiley; 2008. James G. Modern engineering mathematics. 4th ed. Harlow (UK): Pearson Prentice Hall; 2008. Booth S, Woollacott L, Cameron A. Variation in the mastering practices of first-year, South African engineering students: a phenomenographic study. Proceedings of the Second SASEE Conference; 2013; Cape Town, South Africa; 240-293.

Petocz P, Reid A, Wood LM, Smith GH, Mather G, Harding A, Engelbrecht J, Houston K, Hillel J, Perrett G. Undergraduate students' conceptions of mathematics: an international study. Int J Sci Math Ed. 2007;5:439-459. 